AsClepIo. Revista de Historia de la Medicina y de la Ciencia

69 (2), julio-diciembre 2017, p194

ISSN-L:0210-4466

http://dx.doi.org/10.3989/asclepio.2017.17

DOSSIER: ESCENARIOS DE LAS PRÁCTICAS PSIQUIÁTRICAS EN AMÉRICA LATINA (SIGLOS XIX Y XX) / OVERVIEW OF PSYCHIATRIC PRACTICES IN LATIN AMERICA (19 $9^{\text {th }}$ AND $20^{\text {th }}$ CENTURIES)

\title{
EL NIÑO PROBLEMA COMO OBJETO INSTITUCIONAL: LA PSIQUIATRÍA INFANTIL EN CUBA, 1926-1945
}

\author{
Jennifer Lynn Lambe \\ Assistant Professor, Department of History, Brown University \\ Jennifer_Lambe@brown.edu \\ ORCID iD: http://orcid.org/0000-0002-8390-2477
}

Recibido: 07 abril 2017; Aceptado: 01 junio 2017.

Cómo citar este artículo/Citation: Lambe, Jennifer Lynn (2017), "El niño problema como objeto institucional: la psiquiatría infantil en Cuba, 1926-1945", Asclepio 69 (2): p194. doi: http://dx.doi.org/10.3989/asclepio.2017.17

RESUMEN: El nacimiento de la psiquiatría infantil en Cuba en los años 1920 refleja el desarrollo de la psiquiatría como una disciplina con importancia social. La extensión de la pericia psiquiátrica se entrelazó con la figura del "niño problema", quien se concibió como una metáfora para un estado soberano en desarrollo. Pero los reformadores sociales del momento frecuentemente tropezaron con el problema de la corrupción política en sus esfuerzos de rehabilitar a los niños enfermos y delincuentes. Al final, los psiquiatras y activistas que habían concebido al niño problema como un laboratorio poderoso para la regeneración política invertirían la dirección de su lógica causativa: fue el mismo estado que se tendría que rehabilitar para lograr sus metas médicas y sociales.

PALABRAS CLAVE: Psiquiatría infantil; Higiene mental; Cuba; Delincuencia juvenil; Reeducación.

\section{THE PROBLEM CHILD AS INSTITUTIONAL OBJECT: CHILD PSYCHIATRY IN CUBA, 1926-1945}

ABSTRACT: The emergence of child psychiatry in 1920s Cuba mirrored the ascent of psychiatry as a discipline imbued with broader social relevance. The extension of psychiatric expertise was centrally concerned with the figure of the "problem child", posited as a synecdoche for a maturing sovereign state. As reformers set out to rehabilitate mentally ill and "delinquent" children, however, they frequently found themselves running up against the problem of political corruption as it impacted the institutions in which they sought to intervene. Ultimately, psychiatrists and social crusaders who had identified the problem child as a potent site for political regeneration were forced to reverse the causal direction of their reformist logic: it was the state itself that would have to be rehabilitated in order to achieve their medical and social goals.

KEY WORDS: Child psychiatry; Mental hygiene; Cuba; Juvenile delinquency; Reeducation.

Copyright: @ 2017 CSIC. Este es un artículo de acceso abierto distribuido bajo los términos de la licencia Creative Commons Attribution (CC BY) España 3.0. 
“El panorama que en nuestro país ofrece el problema de la niñez desvalida y en peligro, es desconcertante y hasta ahora sin solución aparente." ${ }^{\prime 1}$ Así comienza la llamada reformista de Zenón Zamora y García, uno de los médicos cubanos más importantes de los años 1940. Zamora había dirigido algunas de las principales instituciones hospitalarias de La Habana, pero fue este asunto - el problema del niño desvalido, y del niño problema- el que le preocupó constantemente. Para muchos reformadores de su generación, fue uno de los defectos más indignantes en toda la infraestructura benéfica de Cuba. Para citar a Zamora una vez más, "no [guardaba] relación nuestro estado de progreso y desarrollo cultural, con este punible abandono oficial, que tanto preocupa y atienden los gobiernos y sociedades de los países más civilizados." 2

Son fuertes palabras dirigidas a la oficialidad, a Fulgencio Batista en particular, quien en ese momento había llegado a ser Presidente de la República de Cuba, elegido democráticamente después de casi una década de gobernar desde las sombras. Y este momento político a que pertenece la queja de Zamora representó para muchos la culminación de una generación de activismo a favor de la reforma social progresista, no sólo en el ámbito gubernamental sino en las mismas instituciones oficiales que albergaban, curaban y reeducaban a los que no habían logrado incorporarse al nuevo estado. De ahí la preocupación por el niño problema, futuro sujeto del estado "civilizado" por construir, un proyecto que abarcaba fines terapéuticos, pedagógicos, y correccionales también.

No fue la primera vez en la historia de Cuba que un proyecto de gobernación se entrelazaba con discursos y prácticas de reeducación. A lo largo del siglo XIX, vemos iniciativas - casi siempre limitadas y exclusivistas - para expandir el mundo de la educación, con la idea de renovar el estado colonial o, a veces, combatirlo (Fitchen, 1974; Yero, Agüero García, y Aguiar Blanco, 1989; Franklin, 2012, Cap. 3). La niñez también fue investida con un valor purificador en la retórica de los independentistas que resistían el dominio exterior, primero de España y después de los Estados Unidos. En la transición a la independencia, el impulso pedagógico-político se profundizó, sobre todo a partir de los proyectos educacionales del gobierno interventor estadounidense (1899-1902 y 1906-1909) (Epstein, 1987; Johnston, 1997; Quiza, 2000; Shaffer, 2003; Iglesias Utset, 2003), y a lo largo de las primeras décadas del siglo veinte. Muchas de estas campañas coincidían en su lógica fundamental: que el proyecto de construir un estado nuevo dependía de la salud mental y espiritual de sus ciudadanos futuros. Sin niños sanos, educados y "autodisciplinados" no habría país (Cordoví Núñez, 2012; Rodríguez, 2017; Marqués de Armas, 2014, pp. 142-155). ¿Pero cuándo se convierte lo que nace como un asunto pedagógico en un tema a la vez médico y psiquiátrico? ¿Qué efectos trae la psiquiatrización de la niñez cuando hablamos de proyectos de gobernación?

Este ensayo abarca la interpenetración de los discursos políticos, pedagógicos y psiquiátricos en Cuba $-\mathrm{y}$ sus implicaciones institucionales y políticas - cuando emerge la psiquiatría infantil como una disciplina especializada en los años 1920. A partir de esta coyuntura comienzan varios profesionales médicos a movilizarse a favor de una política más progresista (pero a la vez más disciplinaria) en cuanto al niño enfermo/problema. En sus discursos, se nota siempre una confusión alrededor de esa misma división: cuando se trata del niño anormal, ¿cómo separar la enfermedad de la delincuencia? ¿Quién merece tratamiento y quién castigo? ¿Qué instituciones y paradigmas ayudarán a precisar la diferencia, y proceder correctamente a la curación o reclusión?

Argumento aquí que en Cuba la historia del "niño problema" como fenómeno médico e institucional se entrelaza con paradigmas y problemáticas políticos. La psiquiatría infantil cubana nace en el pleno seno del hospital psiquiátrico en los años 1920, donde los psiquiatras cubanos empezaron a desarrollar una teoría coherente de la enfermedad mental juvenil. Esta etapa clave para la psiquiatría en Cuba se nutrió del progreso contemporáneo de la pedagogía, que buscaba transformar a los niños cubanos en "ciudadanos conscientes que mostraran condiciones para su gobernabilidad" (Cordoví Núñez, 2012, p. 98). Yoel Cordoví Núñez ha subrayado la transcendencia del cuerpo infantil en estos proyectos higienistas, que promulgaban las actividades físicas (desde los deportes y "controles físicos" hasta cierta militarización en los años 1920). Para llegar a un estado de "autocontrol" mental, habría que actuar primero (si no exclusivamente) sobre el cuadro físico del niño. En este contexto no sólo nacional sino internacional, resulta lógico el surgimiento de una psiquiatría infantil que buscaba formas más exactas de llegar al contenido mental del desarrollo infantil.

Pero estas preocupaciones no se limitaron a los espacios institucionales ya indicados: la escuela y el manicomio. Desde el enfoque higienista de educación, optimización, y curación, imbuido del espíritu cívico de un optimismo científico, la psiquiatría infantil pasa rápidamente al terreno más ambiguo de los sujetos 
aparentemente incurables e incorregibles. La sede para estas cuestiones será el reformatorio y a los proyectos asociados a ello en los años 1940, cuando este mismo problema - de aclarar y profundizar las raíces psicológicas y sociales de la delincuencia juvenil- se tropieza con las realidades políticas y sociales de la época. De este modo, el niño problema se convierte en una fuerte metáfora y en un espejo del estado empedernidamente corrupto. Lo que nace entonces como un proyecto microcosmo de regeneración nacional, partiendo del niño para llegar al estado, al fin concluye en que el mismo estado tendrá que ser el objeto primordial de su mirada reformadora.

\section{EL AUGE DE LA PSIQUIATRÍA INFANTIL: CUESTIONES MÉDICAS Y POLÍTICAS}

La historia de la psiquiatría infantil como tal es relativamente corta. Fue solamente a partir de los años 1920 que, en diversos contextos, la psiquiatría empezó a dedicar su atención al niño como sujeto médico distinto, merecedor de sus propios expertos, teorías, y esquemas. Solemos asociar el nacimiento de esta especialidad con el prototipo establecido en los Estados Unidos, incorporando las décadas anteriores de movilización activista y filantrópica. Antes que los psiquiatras empezaran a enfocarse en el "niño" como entidad particular, el campo de los "estudios del niño" reunió a "activistas sociales femeninas, madres organizadas, y científicos reformadores" bajo la misma bandera militante (Boardman Smuts, 2008, p. 3). A partir de esas colaboraciones emergieron nuevas instituciones, dedicadas sobre todo a estudiar, orientar, y rehabilitar a niños normales y anormales, apoyándose siempre en un enfoque interdisciplinario.

En muchos aspectos, la psiquiatría infantil nació de la gran movilización alrededor de la llamada "higiene mental" a comienzos del siglo pasado. Esta corriente, tanto internacional como transnacional, prometió abrir una salida para los psiquiatras que habían languidecido dentro de asilos superpoblados y difamados o los que, en otros contextos, carecían de una plataforma institucional o ideológica para proyectar su autoridad. Aprovechando el optimismo asociado a los nuevos paradigmas sociales, los higienistas planteaban que muchos problemas adultos - sobre todo en el área de la salud mental- se podrían controlar, si no eliminar, a través de una atención preventiva a la juventud. Rompieron, de este modo, con los viejos esquemas biologizantes y degeneracionistas. Éstos habían postulado que la herencia defectiva condenaría a muchos inocentes a sufrir los estigmas men- tales y físicos trasmitidos por sus antepasados. El niño ofreció un sujeto ideal para ejecutar este giro anti-determinista. Concebido como un ente predictivo del futuro individual y colectivo de la adultez, el niño esperaba solamente la mediación experta que se prestaría a guiarlo en la escuela, o quizás rehabilitarlo en la clínica. De este proyecto nació el llamado "niño problema", caracterizado por su conducta rebelde y desafiante (Jones, 1999).

Con el tiempo, la psiquiatría infantil se despojaría de sus orígenes sociales y reformistas, transformándose así en una especialidad profesionalizada y algo exclusivista. Esta transición llevó consigo algunas reorientaciones teóricas. Antes, los postulados ambientales de la higiene mental exigían intervenciones amplias y profilácticas. Los problemas de conducta se concebían, no como aflicciones clínicas e individuales, sino más bien como síntomas de una deformación familiar o contextual. Sin duda, tal enfoque podría implicar cierta patologización social, étnica, o racial, y no pocos higienistas se convirtieron en eugenicistas comprometidos. Pero también imponía retos reformistas: difícil sería ignorar los efectos de la pobreza o la marginalización social en el desarrollo del niño. Luego, la mirada clínica se limitaría mucho más. Formalizada como una rama reconocida de la profesión, la psiquiatría infantil despediría a los otros profesionales y reformistas que habían acompañado su progreso, exaltando la psicoterapia (profesionalmente administrada) como el eje de cualquier intervención (Boardman Smuts, 2008, Cap. 12).

Así ocurrió, por lo menos, en los Estados Unidos, donde el desarrollo de la psiquiatría, con todas sus dificultades y angustias, precedió a la higiene mental como disciplina. Sin embargo, si escudriñáramos el escenario internacional, esa trayectoria se destacaría, no como normativa, sino excepcional. En muchos contextos latinoamericanos, la psiquiatría y la higiene mental nacieron mano a mano, gemelos no solo en términos profesionales sino ideológicamente también. Y en esta unión filial de la psiquiatría latinoamericana se encuentra, como ha propuesto Andrés Ríos Molina, otro hermano clave: el estado intervencionista, y hasta revolucionario (Ríos Molina, 2013, p. 150). En el mismo caso de los Estados Unidos, cuando la psiquiatría infantil se retiró a la clínica psicoterapéutica, su importancia se continuó expresando en términos geopolíticos, como un baluarte profesional contra los peligros de la Guerra Fría, por ejemplo (Smith, 2012, pp. 54-74). Pero en otros lugares, la unión entre la política y el desarrollo de la psiquiatría infantil fue mucho más estrecha. 
El inicio de la psiquiatría infantil en Cuba y su desarrollo como una especialidad de trascendencia partió de una serie de convulsiones del estado, marcadas por el ascenso de dos dictadores infames y la Revolución de 1933 de por medio. Nació, pues, en el seno del paternalismo estadista practicado por Gerardo Machado y Morales (1926-1933), con sus atenciones propagandistas a las instituciones benéficas. Estas intervenciones llegaron a tocar a Mazorra, el manicomio nacional, donde sembraron una eflorescencia médica y fundaron un pabellón para niños. En ese pabellón se institucionalizó por primera vez la atención clínicapsiquiátrica al niño. Pero todas las iniciativas científicas emprendidas bajo Machado cayeron junto con su gobierno en la Revolución de 1933, durante la cual se levantó Fulgencio Batista, un sargento desconocido que volvería a dominar dos veces el estado cubano (la última vez a través de un golpe de estado). Sin embargo, el reino de los dos dictadores provocaría un fenómeno curiosamente contrapuesto: nacería una generación tanto contestataria como partidaria de la reforma social. Fueron ellos quienes lideraron la Revolución de 1933 y, luego, promulgarían una reforma legal y constitucional, basada en principios científicos.

En estos esfuerzos se profundizó el énfasis profiláctico de la higiene mental, esta vez como práctica legal-social. Como en otros sitios latinoamericanos, los reformistas cubanos se inspiraron en los principios del criminólogo positivista Enrico Ferri, estudiante de Cesare Lombroso y promulgador del concepto de la "peligrosidad." Ferri y sus seguidores proponían una práctica criminológica orientada a la prevención en vez del castigo. A lo largo de la década pos-revolucionaria (1934-1940), dominada por las manipulaciones políticas de Batista, la campaña reformista culminaría en el Código de Defensa Social (1936), inspirada por varios ejemplos europeos (Italia y España). El Código se basó fundamentalmente en el concepto de la peligrosidad, rompiendo con la tradición clásica y su énfasis en la responsabilidad. Como bien expresa Ramón Cruz de la Ochoa, "no se trata de un Código de penas, escrito para castigar al delincuente, sino inspirado en el principio de defensa social contra el delito" (Cruz Ochoa, 2000; también ver Marqués de Armas, 2014).

De manera que, una vez más, surge el niño como objeto paradigmático de la intervención médica-legal. Si la psiquiatría infantil en Cuba nació en el manicomio, rápidamente se implantaría en otras instituciones, sobre todo el reformatorio y sus diversos homólogos pedagógicos. ¿Cuál sería su misión? La psiquiatría infantil, igual que la profesión en general, tendría que navegar los asociados pero a veces opuestos imperativos de curación, por una parte, y reeducación y corrección, por otra. Sin embargo, no sería este objetivo contradictorio el que condenaría la psiquiatría infantil a un declive precoz en Cuba. Sería más bien su dependencia en un estado dividido por igual, entre su misión aparentemente reformista y su tendencia a la corrupción y el autoritarismo. La psiquiatría infantil no se resucitará como eje principal de su profesión hasta el nacimiento del estado verdaderamente revolucionario por venir. Después de 1959, los políticos, igual que los psiquiatras, concebirán a la reeducación del niño como un proyecto no solamente terapéutico, sino también ideológico, y de transcendencia social.

\section{EL DESARROLLO INSTITUCIONAL DE LA PSIQUIATRÍA INFANTIL CUBANA}

Antes de articular su misión, la psiquiatría infantil tendría que establecer una sede institucional. En las primeras décadas del siglo XX los administradores de Mazorra, el único hospital psiquiátrico de Cuba, habían luchado - casi siempre sin éxito - para crear pabellones apartes para niños. Como resultado, los niños siempre se encontraban mezclados entre los pacientes adultos. Esta promiscuidad representaba un problema grave para el orden moral, y los médicos de Mazorra frecuentemente lo comentaban como una de sus tribulaciones más mortificantes.

Pero no fue la única. Desde su fundación, el asilo sería un objeto de consternación y desidentificación profesional. Mazorra fue el primer hospital psiquiátrico cubano, construido en 1857 para dar albergue tanto a los enfermos mentales como a los "emancipados", una clase especial de ex-esclavos, que se habían declarado incapaces de trabajar. Esta función doble dotó al hospital de una función custodial que difícilmente se quitaría luego. Los médicos cubanos, muchos de ellos que se habían entrenado en los métodos más modernos del momento, siempre lamentaban que esta institución no sirviera sus fines científicos y profesionales.

La última guerra de independencia (1895-1898) provocó una crisis humanitaria en Mazorra: la mayoría de los pacientes se murieron debido a las escaseces y el abandono. Después de la guerra, y en concierto a veces tenso con el gobierno militar estadounidense que había ocupado la isla, los médicos patriotas convertirían al hospital en un símbolo de los males del pasado colonial y la promesa de una futura soberana para Cuba. A la vez comenzaron un proceso de profesionalización psiquiátrica que daría lugar a nuevas clínicas privadas, un departamento de entrenamiento universitario, e ini- 
ciativas para implementar las novedades terapéuticas más prometedoras del momento. Aun así, el hospital donde en muchos aspectos la psiquiatría cubana había nacido mantendría su infamia. Mazorra no fue solamente una institución médica sino política también; de ser un hospital pública sería siempre vulnerable a las vicisitudes del estado cubano. ${ }^{3}$

El caso de la psiquiátrica infantil institucional sería ejemplar en este aspecto. A principios del siglo, el Dr. Arístides Mestre, médico e hijo de un científico cubano de renombre, había sido testigo de las confusiones provocadas en Mazorra por la falta de recursos adecuados para los niños pacientes. Escribió, por ejemplo, sobre un muchacho internado en la primara sección de adultos tranquilos - un pabellón que, en ese momento, mantenía una sección separada para niños - pero que luego fue reubicado a un pabellón especial para niños anormales. El paciente se quedó allí hasta cumplir quince años, pero mientras tanto la misión del pabellón había cambiado. Durante una epidemia de enteritis en el hospital, lo habían recuperado como un pabellón de adultos, y los niños habían sido devueltos a la sección de adultos tranquilos. Y, debido al crecimiento de su población, las niñas pacientes habían salido del departamento de mujeres para entrar en la sección de mujeres ancianas, donde se quedaron hasta el año $1926 .{ }^{4}$

Pero la movilización de psiquiatras bajo el mandato del Presidente Gerardo Machado abriría espacio para una nueva campaña en nombre de los niños pacientes. Las renovaciones institucionales emprendidas por su gobierno surgieron a raíz de un huracán devastador en el año 1926, que dejó al hospital en un estado muy vulnerable. Más influyente, sin embargo, fue una serie de sucesos políticos que debilitaron profundamente al Presidente, en la medida en que sus esfuerzos anticonstitucionales para prolongar su mandato desataron la violencia política. Machado, pues, empieza a enfocarse en las instituciones benéficas como posible camino a la rehabilitación política, con el notorio manicomio nacional como eje de su campaña. En eso será apoyado - a veces paradójicamente - por la primera generación de psiquiatras entrenados en Cuba, que por muchos años habían militado por la reconstrucción de Mazorra. Su colaboración institucional producirá cambios bastante profundos, incluyendo siete pabellones nuevos. Uno de ellos será el pabellón "Antonio Mestre" de psiquiatría infantil.

Hubo también una lógica profesional para este enfoque en los niños, sobre todo la movilización alrededor de la profilaxis psiquiátrica y su nueva sede en
Cuba, la Liga de Higiene Mental. Por mucho tiempo relegado a los márgenes no solamente médicos sino sociales, la psiquiatría cubana buscaba una plataforma para lanzarse a una nueva transcendencia cultural. La higiene mental representaba un vehículo prometedor. Así lo planteó el Dr. Pablo F. Lavín en 1929 en una conferencia de radio, donde profetizó que la Liga sería "la más poderosa institución política-social de defensa colectiva." ${ }^{5}$ La Liga concibió su misión de una forma expansiva, extendiéndose desde la higiene en el trabajo hasta en las áreas rurales de Cuba. El mismo Presidente Machado la elogiaría como una institución de "utilidad pública."

Este proyecto ambicioso de higiene mental llegaría a los ciudadanos de Cuba a través de los medios de comunicación, tanto de la prensa diaria como de la incipiente cultura de la radio. Consideremos, por ejemplo, una conferencia radial de Juan Portell Vilá sobre el tema de "La higiene mental y el contagio psíquico de las multitudes", transmitida por la Estación C.M.K. en septiembre de 1929. Resumiendo las teorías clásicas de la mentalidad del grupo, Portell Vilá exhortaba al público a cultivar el equilibrio mental, no sólo como víctimas potenciales del "contagio psíquico", sino como aliados posibles en la lucha para combatirlo: "temblad entonces queridos radioyentes, porque siguiendo las leyes inmutables de la Naturaleza en el terreno físico, donde se comprueba siempre el horror al vacío, de la misma manera se cumplirán estas leyes en el terreno psíquico y sin que podáis evitarlo, os veréis obligados a permanecer como el amigo, como el mentor y hasta como el confesor de estos pacientes que necesitan de los beneficios que reportan los Dispensarios de Higiene y Profilaxis Mental."6 El proyecto de la higiene mental dependería tanto de los expertos como de los ciudadanos en su misión para promover el bienestar colectivo.

Los psiquiatras cubanos iniciaron esta campaña de acuerdo con sus colegas internacionales, que ofrecían modelos previos y consejos sabios en el transcurso. Reflejando estos vínculos, Cuba mandó tres delegados al Primer Congreso Internacional de la Higiene Mental (Washington, D.C., mayo de 1930), en el cual visitaron la famosa clínica de Adolf Meyer en Baltimore (además del zoológico del Bronx, el Museo de la Historia Natural en Nueva York, y Coney Island). Uno de los delegados cubanos, René de La-Valette, dio una presentación en inglés sobre una iniciativa que cultivaría el tratamiento psiquiátrico ambulatorio. Todos se inspiraron por el evento. De regreso a Cuba, lanzaron una serie de reformas basadas en sus experiencias estadounidenses y sus contactos mundiales. ${ }^{7}$ 
Pero a pesar de su entusiasmo por la higiene mental, los psiquiatras cubanos no disfrutaban de un perfil social suficientemente amplio para proyectarse fuera del manicomio, para así alcanzar a los cubanos "normales" o a los meramente neuróticos. Por eso se verán limitados a experimentar dentro de las paredes institucionales $y$, sobre todo, a experimentar en sus poblaciones juveniles, las cuales eran entendidas como un conducto profiláctico al mundo adulto. En el nuevo Pabellón "Antonio Mestre", buscarían un modelo teórico para resolver un problema tanto administrativo como social: cómo transformar a los niños problemáticos en ciudadanos futuros, "útiles a la Patria y a la Sociedad."8

Bajo el liderazgo de los Dres. Arístides Mestre y Juan Portell Vilá, estrenaron el pabellón en 1927 para recibir un número siempre bajo, pero simbólicamente importante, de muchachos. Los trabajos científicos publicados por los dos médicos ofrecen una perspectiva de la composición de esta población juvenil, que en 1931 incluyó a catorce niños y a cuatro niñas, algunos de ellos veteranos de la institución. Un habanero de dieciséis años, por ejemplo, había llegado al hospital con cuatro años y vivió una década entre la población general adulta. Otro muchacho, diagnosticado con "idiotez", había entrado con solamente dos años de edad. Pero las experiencias previas y clasificaciones psiquiátricas de los pacientes fueron marcadamente diversas, con una incidencia siempre notable de epilepsia, "imbecilidad", incontinencia, "excitación" y agresividad. Algunos revelaron hasta instintos homicidas: una muchacha trató de estrangular a otro paciente, y otro niño expresó un deseo matricida. Aunque los médicos solían poner más énfasis en la trayectoria neuropsiquiátrica de los casos, Mestre también daba algunos detalles sobre sus estados mentales: eran nerviosos, tranquilos, de "emotividad intensa", y había un muchacho de diez años con "tendencia homosexual."

Enumerando los progresos recientes, Mestre expresó su satisfacción al ver a todos los niños de Mazorra "asistidos con afecto y con el propósito de aliviarles en lo posible el peso de su herencia." ${ }^{10}$ En el futuro, esperaban asimilar todos los pasos de institucionalización bajo la autoridad médica, y no judicial. Sin embargo, mientras tanto, propusieron empezar un proceso no solamente curativo sino también reeducacional: erradicar las "anomalías intelectuales", "del carácter", y "de la moralidad" que muchas veces observaron. ${ }^{11}$

Para apoyar estos planes desarrollaron programas rigurosos de diagnósticos y tratamiento. Después de los exámenes preliminares, los empleados inicia- ban una etapa de observación, vigilando al paciente mientras comía, jugaba, y hasta dormía. También administraban pruebas para calcular la extensión de su vocabulario, su capacidad para discernir objetos y la anatomía humana con sus habilidades físicas, pero siempre con la idea de mantenerlo aislado y lejos de toda distracción.

Luego procedían a un diagnóstico de suma importancia, la llamada "casa de prueba", que impulsaba un ejercicio de reconocimiento doméstico: "Al día siguiente, en nuestro Salón Pedagógico, situamos al niño frente a una casita de madera cuyo tamaño alcanza más de un metro de largo por medio de ancho y de una altura proporcionada a la base. Esta casita en miniatura, con su portal, puertas y ventanas, con tabiques interiores y otros detalles ornamentales... está colocada sobre una mesa y a una altura conveniente para que el niño la pueda examinar con detención. Si el caso lo requiere, nos retiramos del Salón y dejamos al niño a solas con la casita para desde otro lugar y sin ser visto por él, poder observar su comportamiento para estudiar la repetición de sus movimientos, abriendo y cerrando las puertas y ventanas, la introducción de sus manos para saciar sus curiosidad táctil, etc."12 Sin duda, este régimen de juego y observación cumplía una función estérilmente clínica para sus elaboradores, pero no evitó por eso algunos ecos familiares: interpelados precisamente como niños e invitados a explorar un simulacro doméstico, ¿cómo habrían reaccionado los niños pacientes de Mazorra, despojados de sus propias raíces familiares?

El contrapunteo entre estas evocaciones clínicas y, a la vez, domésticas ejemplifica la misión primordialmente doble de la psiquiatría infantil. Por un lado, los psiquiatras que la lideraban buscaban en ella una plataforma médica: para llegar al futuro paciente "normal", habría que trabajar primero con el niño trastornado y muchas veces desprovisto de su propia estructura social-familiar. Es decir, el niño paciente, identificado como tal, servía fines tanto intelectuales como profesionales. Sin embargo, no era posible aislar esta misión científica de sus implicaciones sociales. Al sumar (aunque involuntariamente) la identidad de "paciente", el niño entraba en un nuevo espacio identitario en el que la autoridad adulta residía en su médico. Así tanto paciente como psiquiatra atravesaron un proceso no solamente de tratamiento, sino de (re-) socialización. En su trabajo científico en el Pabellón Antonio Mestre, los psiquiatras tendrían que navegar este papel doble - padre/médico- aún cuando insistieran en el último. Trabajando para introducir las 
terapias experimentales más ocurrentes entre los niños del departamento, el Dr. Portell Vilá mantendría su énfasis en el avance científico sobre todo, pero de tal forma que se inmiscuía en las prerrogativas paternas tradicionales.

Fijémonos en un experimento especialmente sugerente: inspirado por el ejemplo de Henri Wallon en París, el Dr. Portell Vilá decidió administrarles un nuevo medicamento a dos niños en su pabellón, la Bulbocapnina de Merck. Una droga de cierta notoriedad (William S. Burroughs le atribuía el poder de inducir a la obediencia en Naked Lunch), la Bulbocapnina es un alcaloide que inhibe la producción natural de dopamina. La misma inspiraría años de experimentación psiquiátrica a partir de los años 1920. Numerosos investigadores fuera de Cuba habían explorado su capacidad de provocar catalepsia en los gatos y monos. ${ }^{13}$ Pero Portell Vilá, junto con sus colegas internacionales, se había interesado en sus posibles aplicaciones humanas, sobre todo en el impacto de dosis pequeñas en la actividad psicomotor.

Fue con un nuevo sujeto psicopedagógico -el niño "turbulento" - que la Bulbocapnina recibiría su primera prueba en la psiquiatría cubana. Fuera de Cuba, la idea de la turbulencia infantil había emergido como una base teórica para muchas intervenciones profesionales en el comportamiento de los niños. Así unía los aspectos somáticos y psíquicos de una conducta problemática. Según Portell Vilá, inspirado por Wallon, el niño turbulento "[manifiesta] todas las características inquietantes de los pequeños psicópatas, pero sin arraigar en ellos la peligrosidad instintiva de los niños perversos y de los epilépticos." ${ }^{14}$ Por eso debía ser susceptible a los efectos de un medicamento que llegara a las dimensiones orgánicas y emotivas de su condición.

Portell Vilá inició la prueba con un muchacho "turbulento" de doce años, empezando con una dosis de cinco centigramos, que elevaría a diez centigramos al día siguiente $y$, dos días después, a veinte centigramos. Treinta minutos después de la última administración, el paciente empezó a vomitar, sudar, y sufrir modificaciones pupilares. Su médico no se dejó asustar: una hora después, el niño "almorzó tranquilamente y se entretuvo en el patio de recreo como de costumbre aunque algo aumentada su vivacidad infantil."15 Pero el impacto psicológico de la Bulbocapnina fue aún más impresionante. Nota Portell Vilá que había estimulado sobre su paciente una naciente "ideología suntuaria y altruista", caracterizada por sus "apetencias artísticas." ${ }^{\prime 16}$ Después de la administración de diez centigramos, el niño, "sin modificaciones aparentes de su actividad psico-motriz sintió una vez la necesidad de escalar la cerca de alambre del fondo del patio de recreo del Pabellón, vigilar la situación estratégica de los vecinos de una casa colindante, penetrar a hurtadillas en la sala de visita, trasladar cuidadosamente un tiesto con una planta de adorno y que luego depositó en el Saloncito de Consultas de nuestro Pabellón a los pies mismos de donde me encontraba escribiendo." ${ }^{17}$ Así entra el niño turbulento en la escena privada del consultorio médico.

Portell Vilá y la enfermera que lo acompañaba se declararon encantados e impresionados frente a las explicaciones del niño. Les dijo que había traído la planta para "hacer bonito [sic]", prueba, según Portell Vilá, de un impulso cleptomaniaco canalizado por un "acto de desagravio con todos los rasgos de una ideología suntuaria y altruista." ${ }^{18}$ Esto comprobaba, entonces, la eficacia del medicamento, y su capacidad de alterar los aspectos psicológicos y fisiológicos de la condición de turbulencia. He aquí una declaración ambiciosa de que un medicamento, al actuar sobre el cuerpo del niño, podría reorientar un instinto antisocial hacia fines altruistas. La fascinación del niño con objetos decorativos lo podría haber impulsado a robar, pero con la idea de embellecer la estéril clínica del médico.

Así vemos de nuevo una acción recíproca en las intervenciones clínicas de la psiquiatría infantil. A la vez que Portell Vilá establecía los efectos psicológicos y hasta morales de un medicamento que actuaba sobre el cuerpo, sus consecuencias transcendentales se manifestaban en un contexto interpersonal, en el que el mismo médico se ubica como receptor humano de las atenciones - purgadas ahora de implicaciones criminales - del niño. La eficacia de una intervención somática, de penetrar en el mundo mental y moral del niño, se mide en la misma interpretación que hace Portell Vilá de la acción del niño en cuanto a sus implicaciones para el médico. Para expresarlo de otra forma, no es el comportamiento del niño —-todavía erróneo en muchos aspectos - que ha cambiado en la clínica psiquiátrica, sino su significado moral e interpersonal. Y la articulación de ese cambio nos trae de nuevo a la figura de Portell Vilá.

Cuando se trataba del niño, Portell Vilá propugnaba una intervención agresiva de regulación, hasta con los niños "normales." Adaptando una gran variedad de perspectivas teóricas - el behaviorismo Watsoniano, la endocrinología, la neuropsiquiatría y el psicoanálisis- planteaba que los educadores debían usar to- 
dos los medios disponibles para retardar y canalizar el desarrollo de la sexualidad juvenil. Insistía que un niño precoz se debía aislar de todas las posibles provocaciones, como los libros románticos, las películas, la música (Chopin fue especialmente alarmante), los perfumes afrodisíacos, y los ejercicios gimnásticos estimulantes. El objetivo debía ser la regulación total de todas sus experiencias sensoriales. ${ }^{19}$

Pero cuando se trataba de niños "anormales" y "perversos", Portell Vilá postulaba que los mecanismos regulares no bastarían. En este caso, haría falta la intervención médica profesional para establecer las raíces somáticas (si existían) del problema moral.

Podríamos decir que esta problemática corresponde a aquella elaborada por el Dr. Arístides Mestre varios años antes. En su presentación frente al V Congreso Panamericano del Niño con sede en La Habana, Mestre había propuesto un esquema de delincuencia juvenil con manifestaciones "sociales" y "patológicas." Los delincuentes patológicos se podrían dividir además entre los "perversos o viciosos" y los "pervertidos o viciados." La diferencia entre los dos grupos radica en el uso del participio pasado con el último. Dice el Dr. Mestre que "sufre el perverso de una defectuosidad constitucional más o menos intensa de los instintos primitivos: es un estado endógeno que al mal predispone directamente; mientras que el pervertido, si bien tiene en buenas condiciones esos instintos, en cambio se presentan oscurecidos o desviados por causas exógenas." ${ }^{20}$ Vasto sería el campo de producción académica en esta área, donde los especialistas forenses y los psiquiatras cubanos encontrarían mucho terreno intelectual en común.

Pero fue precisamente en su frontera compartida donde se hicieron más opacas las diferencias diagnósticas. ¿Quién necesitaba tratamiento médico y quién reeducación o resocialización? ¿Cómo establecer la diferencia? A pesar del evidente desarrollo del campo médico, sería limitado el impacto de la psiquiatría infantil, con sus fines tanto terapéuticos como correccionales. El número de pacientes que entraron en la Sala "Mestre" se mantendría siempre a un nivel bajo, ${ }^{21}$ y fueron pocas las instituciones homólogas que se inspiraron por su ejemplo. ${ }^{22}$ Para seguir entonces la trayectoria del "niño problema" a lo largo de la Segunda República (1933-1958), tenemos que abrir las puertas de los siempre malignados reformatorios de La Habana, donde la mayoría de ellos terminaron. Aquí se continúa y resucita la polémica sobre el tratamiento del comportamiento equivocado y sus posibles raíces mentales, pero con consecuencias poco satisfactorias.

\section{¿NIÑO PROBLEMA O PROBLEMA DE ESTADO?}

Regresemos entonces al contexto reformista que surgió a partir de la frustrada Revolución de 1933. Dicho periodo buscaba derrocar la dictadura de Gerardo Machado pero desembocó en el ascenso de otro dictador, Fulgencio Batista, quien gobernaría primero detrás del telón (1934-1940), luego como Presidente democráticamente elegido (1940-44), y finalmente como dictador impuesto mediante un golpe de estado (1952-59). Pero las maquinaciones políticas de Batista no impidieron que una generación reformista promulgara sus proyectos de regeneración médico-legal. Su iniciativa rindió frutos en un nuevo Código de Defensa Social, que buscaba reorientar la práctica criminológica hacia la profilaxis en vez del castigo (Ameringer, 2000; Whitney, 2000; Marqués de Armas, 2014; Lambe, 2017).

Desde hacía mucho tiempo el niño delincuente inspiraba proyectos preventivos en Cuba. No pocos criminólogos y médicos cubanos citarían a un cubano, Erasmo Regüeiferos, como uno de los primeros en "[plantear]...el problema de los menores desvalidos y delincuentes." ${ }^{23}$ Pero en la práctica la influencia de la criminología se sentía más en el ámbito institucional. Los reformatorios establecidos y renovados por el gobierno norteamericano durante su primera y segunda ocupación de la isla (1899-1902 y 1906-09) engendraban durante muchos años desilusiones y decepciones. En esas facilidades los sueños reeducacionales se tropezaban, generación tras generación, con sus realidades carcelarias. Periodistas, reformadores, políticos, e, incluso, sus propios empleados, lamentaban que los reformatorios sufrieran escasez material y, más seriamente, infamias morales. Lo que faltaba, según sus críticos, era una organización más científica, fortalecida por un estado activo y resuelto: un paradigma médico y legal orientado a la rehabilitación.

En esta pugna, suscitada durante décadas por criminólogos, pedagogos, y abogados, intercede el espíritu renovador de los años 1930. Imbuido con los nuevos principios de profilaxis y, a la vez, de caridad para los niños "desvalidos" y "delincuentes", los expertos de la beneficencia pública se movilizaron para convertir los antiguos reformatorios en establecimientos científicos y humanos. De allí salió la orden del Coronel Batista a reubicar el antiguo reformatorio de niños (antes llamado Guanajay) a la finca "Torrens" (el nombre que después llevará), y donde estrenarían el nuevo "Centro de Orientación Infantil" en 1938. ${ }^{24}$

Este paso importante pretendía ser el comienzo de una renovada política de reeducación y regeneración 
infantil en Cuba. Coincidía con nuevos paradigmas médicos y legales que ponían énfasis en las raíces ambientales de la delincuencia juvenil. Con cierto optimismo social, perseguía una perspectiva multidisciplinaria uniendo a psiquiatras, psicólogos, médicos, abogados, y pedagogos - para un problema anteriormente intratable. Sus partidarios postulaban lazos cada vez más estrechos entre los tribunales y los reeducadores, para prevenir que el niño que había cometido un crimen cayera en el mundo carcelario adulto.

La misión del nuevo Centro de Orientación Infantil fue apropiadamente ambiciosa, pues establecía en su reglamento las "funciones de protección, amparo, educación y asistencia de los niños, de ambos sexos, huérfanos, en peligrosidad, desvalidos o que ejerzan la mendicidad, y la de prepararlos adecuadamente en las aulas talleres, centros agrícolas y demás departamentos de que conste el Centro, propendiendo a la re-educación de los mismos...toda clase de medidas, iniciativas y propósitos y que tiendan a cuidar, amparar, proteger y curar a los niños y adolescentes anormales." ${ }^{25}$ Esta enorme labor científica se debería catalogar en hojas clínicas extensas. Una versión de nueve páginas elaborada por el Dr. Enrique Henríquez - su "Ficha psico-bio-social para menores delincuentes" - proponía clasificar a los menores delincuentes en los púberes e impúberes, los normales (ocasionales y habituales) y los anormales (orgánicos, psicópatas, oligofrénicos, mixtos); de los anormales, los que eran curables, modificables, o incurables; de los normales ocasionales, los que habían delinquido "por ineducación", "por imitación", "por inducción", "por abandono moral", o "por necesidad moral"; y de los normales habituales, los que habían cometido crímenes "por necesidad moral o material permanente", "por influencia mesológica", o "por tendencia adquirida incorregible." ${ }^{26}$ No fue solamente una nueva perspectiva médica que se esperaba implantar en esta labor reeducacional, sino jurídica también. Muchos reformadores renovaron la campaña para establecer "tribunales de menores" especializados. ${ }^{27}$ Pero esto no se lograría hasta los años 1950, cuando el Centro de Orientación Infantil estrenó el primer tribunal para menores, en el que los muchachos internados servían como jueces. ${ }^{28}$ Mientras tanto, los sueños ambiciosos de Zamora, Henríquez, y muchos más, incluyendo los de la élite habanera que veían en la delincuencia juvenil una causa social de importancia, quedaron prácticamente en la nada.

El Centro de Orientación Infantil sería durante todos los años 1930, 40, y 50 acosado por acusacio- nes de maltratos, "promiscuidad" de sus internados (varias alegaciones de homosexualidad también se encuentran entre las publicaciones de la época), y desorganización administrativa y científica. Un mundo aparte, entonces, de la promesa regenerativa del Código de Defensa Social. ${ }^{29}$ Algunos guardaban la esperanza de que el estado cubano - sea en manos de Batista y sus sucesores democráticamente elegidos en el Partido Auténtico- se responsabilizaría de la institución difamada. Pero esas ilusiones tampoco se reflejarían en la realidad. Los reformatorios, igual que el estado que los debiera haber respaldado, seguirían plagados de corrupción, escasez, y decepciones (Ameringer, 2000; Whitney, 2000).

\section{CONCLUSIÓN}

En Cuba, esta primera etapa de atención interdisciplinaria al niño quedaría como uno de los muchos sueños frustrados de sus partidarios reformistas. Armado con un equipo experto en todos los aspectos del "niño problema", habían luchado para establecer un tratamiento especializado a sus distintas manifestaciones, con raíces tanto médicas como sociales. Pero las instituciones que hospedaban sus esfuerzos no estaban a la altura de su labor. Quedaría para otra generación reformista asumir el cargo, esta vez apoyada por un nuevo estado revolucionario. Después de 1959, el proyecto para rehabilitar al niño problema se destacaría como una de las preocupaciones más transcendentales de la psiquiatría cubana. En esto, encontró un patrocinador ideal en el propio estado revolucionario. Los jóvenes cubanos se interpelarían como los sujetos ideales del mismo proyecto revolucionario, y los defensores naturales de su misión política. Fueron movilizados para participar en su campaña alfabetizadora y otras iniciativas de los años 1960, encarnando así sus papeles como los hijos e hijas espirituales del estado (Sutherland Martínez, 1959; Casavantes Bradford, 2014).

Sin embargo, no todos llegaron a esta identificación política y social de una forma instantánea. Muchos jóvenes forjaron su convicción política a través de la actividad política y las organizaciones de masa, pero otros se relacionaban con el estado en una forma diferente. De nuevo surgiría el hospital psiquiátrico $-\mathrm{y}$ el reformatorio igualmente- como microcosmo de la labor política de la Revolución. Y una vez más la psiquiatría, junto con el campo vasto de la reeducación, se prestaría para convertir a los "niños problemas" no solamente en niños sanos, sino en participantes en el nuevo orden político. 


\section{NOTAS}

1. Zamora y García, Zenón (1945), Orientación infantil, Havana, p. 5.

2. Zamora y García (1945), p. 5.

3. Para la historia de Mazorra ver Lambe (2017), Marqués de Armas (2014)

4. Mestre, Aristídes (1931), “El Pabellón de Niños 'Dr. Antonio Mestre', de Mazorra", Revista de psiquiatría y neurología 3, núm. 1-6, pp. 30-36.

5. Lavín, Pablo F. (1929), "Conferencia por Radio explicando los fines de la Liga de Higiene Mental de Cuba", Revista de psiquiatría y neurología 1, núm. 2, p. 57.

6. Portell Vilá, Juan (1929), "La psicología de las multitudes", Revista de psiquiatría y neurología 1, núm. 3, p. 87.

7. Rodríguez Machado, Miguel y De La-Valette, René y Portell Vilá, Juan (1930), "Recorrido Científico después del Primer Congreso Internacional de Higiene Mental", Revista de psiquiatría y neurología 2, núm. 1-3, pp. 3-21.

8. Portell Vilá, Juan (1930), “Las Discordancias Fisiognómicas y la Resonancia Mental en los Niños Anormales", Revista de psiquiatría y neurología 2, núm. 4-6, p 36.

9. Mestre, Arístides (1931), “El Pabellón de Niños 'Dr. Antonio Mestre', de Mazorra", Revista de psiquiatría y neurología 3 , núm. 1-6, pp. 30-36.

10. Mestre (1931), p. 36

11. Mestre (1931), p. 30

12. Portell Vilá, Juan (1931), “La educación médico-pedagógica en el Pabellón de Psiquiatría de la Infancia del Hospital de Mazorra", Revista de psiquiatría y neurología 2, núm. 1112 , p. 133

13. Por ejemplo, Ingram, W.R. and Ranson, S.W. (1934), "Bulbocapnine: Effect on Animals with Lesions of the Central Nervous System", Archives of Neurology and Psychiatry, 31, núm 5, pp. 987-1006; Curt P. Richter and Paterson, Arthur S. (1931), "Bulbocapnine Catalepsy and the Grasp Reflex", The Journal of Pharmacology and Experimental Therapeutics 43, núm. 4, pp. 677-691; Ferraro, Armando and Barrera, Severo Eugene (1932), Experimental Catalepsy: The Action of Bulbocapnine in Cats and Monkeys with the Various Experimental Lesions of the Nervous System, Utica, N.Y, State Hospitals Press.

14. Portell Vilá, Juan (1931), "Informaciones Cliníco-Prácticas. Un niño turbulento tratado por la Bulbocapnina", Revista de neurología y psiquiatría 3, núm. 1-6, p. 37.
16. Portell Vilá (1931), p. 38.

17. Portell Vilá (1931), p. 38.

18. Portell Vilá (1931), p. 38

19. Portell Vilá, Juan (1929), “La profilaxis de las enfermedades venéreas y la neuropatología sexual en los niños", Crónica médica-quirúrgica de la Habana 55, núm. 2, pp. 53-61.

20. Mestre, Arístides (1928), "El Niño Delincuente. Métodos para su Estudio", Revista de Medicina Legal 7, núm. 8, p. 297.

21. Por ejemplo, en 1936 la sala contaba con solamente dieciséis niños y trece niñas. Ver Carta del Dr. Manuel Martí al Sr. Dir. de Beneficencia, 24 de septiembre de 1936 (1 de noviembre de 1936), publicada en el Archivo y Revista de Hospitales 2, núm. 3, pp. 205-207.

22. Una excepción sería el Instituto de Re-educación Física y Mental establecido en 1943 por los Dres. Alberto Inclán y Víctor Santamarina para tratar a niños "inválidos físicos y retardados mentales." Ver Inclán, Alberto y Santamarina, Víctor (Habana, 1943), Instituto de Re-educación Física y Mental. Para el tratamiento de niños inválidos físicos y retardados mentales, consultado en el Museo Histórico de las Ciencias "Carlos J. Finlay", Habana, Cuba.

23. Henríquez, Enrique C. (La Habana, 1944), Orientación infantil y prevención social en Cuba, 31, consultado en la National Library de Medicine, Bethesda, Maryland, EE.UU.

24. Zamora (1945), pp. 8-9.

25. Zamora (1945), p. 33.

26. Henríquez (1944), p. 43.

27. Ver, por ejemplo, la campaña del Dr. Félix García Rodríguez, Director de Beneficencia, sostenida en las revistas médicas de la época, para fundar tal tribunal ["Sobre creación inmediato y provisional de un Tribunal de Menores", 1 de noviembre de 1936), Archivo y Revista de Hospitales 2, núm. 3, p. 189.

28. Reyes Gavilán, Alberto (25 de octubre de 1953), “Funciona en Cuba el primer tribunal de menores", Bohemia 45, núm. 35 , pp. 40-42. No se sabe si este primer paso después se institucionalizó de una forma más expansiva.

29. Penichet, Antonio (12 de marzo de 1944), "Nuestra visita al Instituto de Reeducación de Varones", Carteles 25, núm. 11, p. 16 .

15. Portell Vilá (1931), p. 39. 


\section{BIBLIOGRAFÍA}

Ameringer, Charles D. (2000), The Cuban Democratic Experience: The Auténtico Years, 1944-1952, Gainesville, University Press of Florida.

Boardman Smuts, Alice (2008), Science in the Service of Children, 1893-1935, New Haven, Yale University Press.

Casavantes Bradford, Anita (2014), The Revolution Is for the Children: The Politics of Childhood in Havana and Miami, 1959-1962, Chapel Hill, University of North Carolina Press.

Cordoví Núñez, Yoel (2012), “Cuerpo, pedagogía y disciplina escolar en Cuba: dispositivos de control desde los discursos higienistas (1899-1958)", Tzintzun, 56 (julio-dic.), pp. 93-136

Cruz Ochoa, Ramón de la (2000), “El delito, la criminología y el derecho penal en Cuba después de 1959", Revista Electrónica de Ciencia Penal y Criminología, 2, [en línea], disponible en: http://criminet.ugr.es/recpc/recpc_02-02.html, [consultado el 13/9/2016]

Epstein, Erwin H. (1987), "The Peril of Paternalism: The Imposition of Education on Cuba by the United States", American Journal of Education, 96 (2), pp. 1-23.

Fitchen, Edward D. (1974), "Primary Education in Colonial Cuba: Spanish Tool for Retaining 'La Isla Siempre Leal'?", Caribbean Studies, 14 (Abr.), pp. 105-120.

Franklin, Sarah F. (2012), Women and Slavery in Nineteenth-Century Colonial Cuba, Rochester, University of Rochester Press.

García Yero, Olga; Agüero García, Ernesto y Aguiar Blanco, Aracely (1989), Educación e historia en una villa colonial, Santiago de Cuba, Editorial Oriente.

Iglesias Utset, Marial (2003), Las metáforas del cambio en la vida cotidiana: Cuba, 1898-1902, La Habana, Ediciones Unión.
Johnston, Laurie (1997), "Cuban Nationalism and Responses to Private Education in Cuba, 1902-1958". En: Fowler, Will (ed.) Ideologues and Ideologies in Latin America, Westport, CT, Greenwood Press, pp. 27-45.

Jones, Kathleen W. (1999), Taming the Troublesome Child: American Families, Child Guidance, and the Limits of Psychiatric Authority, Cambridge, Harvard University Press.

Lambe, Jennifer (2017), Madhouse: Psychiatry and Politics in Cuban History, Chapel Hill, University of North Carolina Press.

Marqués de Armas, Pedro (2014), Ciencia y poder en Cuba: racismo, homofobia, nación (1790-1970), Madrid, Editorial Verbum.

Quiza, Ricardo (2000), “El ojo que te ve: discurso clínica y cirugía social en la escuela cubana (1902-1930)", Rábida, 19, pp. 49-52.

Ríos Molina, Andrés (2013), “'Dictating the Suitable Way of Life': Mental Hygiene for Children and Workers in Socialist Mexico, 1934-1940", Journal of the History of the Behavioral Sciences, 49 (2), pp. 142-166.

Rodríguez, Daniel (2017), “'The dangers that surround the child': Gender, Science, and Infant Mortality in Postindependence Havana", Cuban Studies, 45, pp. 297-319.

Shaffer, Kirwin (2003), "Freedom Teaching: Anarchism and Education in Early Republican Cuba, 1898-1925", The Americas, 60 (2), pp. 151-183.

Smith, Matthew (2012), Hyperactive: The Controversial History of $A D H D$, London, Reaktion Books.

Sutherland Martínez, Elizabeth (1969), The Youngest Revolution: A Personal Report on Cuba, New York, Dial Press.

Whitney, Robert (2000), State and Revolution in Cuba: Mass Mobilization and Political Change, 1920-1940, Chapel Hill, The University of North Carolina Press. 